\title{
Maximal work capacity in relation to nutritional status in children with cystic fibrosis
}

\author{
V.A.M. Gulmans*, K. de Meer**, H.J.L. Brackel+, P.J.M. Helders*
}

Maximal work capacity in relation to nutritional status in children with cystic fibrosis. V.A.M. Gulmans, K. de Meer, H.J.L. Brackel, P.J.M. Helders. @ERS Journals Ltd 1997. ABSTRACT: In children with cystic fibrosis, objective parameters of exercise tolerance are needed which are easy to measure in nonspecialized centres. We investigated maximal workload $\left(W^{\prime} \max \right)$ in children with cystic fibrosis in relation to body weight and fat-free mass, and compared this with results for maximal oxygen consumption $\left(V^{\prime} \mathrm{O}_{2}, \mathrm{max}\right)$.

Fourteen patients with cystic fibrosis performed an incremental maximal exercise test on a bicycle ergometer. $W^{\prime} \max , V^{\prime} \mathrm{O}_{2}, \max$, body weight and fat-free mass were measured.

$W^{\prime} \max$ and $\mathrm{V}^{\prime} \mathrm{O}_{2}$, max were significantly correlated $(\mathrm{r}=0.91 ; \mathrm{p}<0.001)$. Using standard deviation scores in relation to reference values, $W^{\prime} \max$ and $V^{\prime} \mathrm{O}_{2}$, max per kilogram body weight were significantly higher than uncorrected $W^{\prime} \max$ and $V^{\prime} \mathrm{O}_{2}$, max (mean difference $(95 \% \mathrm{CI}) \mathbf{0 . 6 3}(0.24-1.01)$ and $0.91(0.32-1.49)$ SD units, respectively). There was no such difference after correction for fat-free mass. Standardized $V^{\prime} \mathrm{O}_{2}$, max was significantly higher than standardized $W^{\prime} \max$ (mean difference $(95 \% \mathrm{CI}): 1.59(1.14-2.04)$ ), also after correction for body weight and fat-free mass.

In children with mild-to-moderate cystic fibrosis, maximal workload per kilogram fat-free mass, but not per kilogram body weight, is a useful parameter to correct for diminished nutritional status. In these patients, maximal workload is consistently lower than maximal oxygen consumption. Taking into account this difference, maximal workload and maximal workload per kilogram fat-free mass can be used for follow-up of paediatric patients with cystic fibrosis in nonspecialized settings. Eur Respir J 1997; 10: 2014-2017.
Depts of *Paediatric Physiotherapy, **Gastroenterology and +Respiratory Diseases, Wilhelmina Children's Hospital, University Hospital for Children and Youth, Utrecht, The Netherlands.

Correspondence: V.A.M. Gulmans Dept of Paediatric Physiotherapy Wilhelmina Children's Hospital University Hospital for Children and Youth P.O. Box 18009

3501 CA Utrecht

The Netherlands

\section{Keywords: Children}

cystic fibrosis

exercise

nutritional status

Received: November 71996

Accepted after revision May 91997

Presented at the annual congress of the European Respiratory Society, 1995, Barcelona, Spain.
In patients with cystic fibrosis $(\mathrm{CF})$, deterioration of lung function and nutritional status is often seen, and clinical deterioration in these patients is associated with decreased exercise tolerance. Nutritional status and exercise tolerance in $\mathrm{CF}$ patients are associated with prognosis and survival $[1,2]$, and their preservation is thus important [3]. Exercise programmes have been shown to improve exercise tolerance in children and adults with $\mathrm{CF}$ [4-12]. For monitoring of exercise programmes in individual patients, easy and reliable measurements of exercise capacity with correction for nutritional status are needed. However, adequate methods to this purpose are not readily available.

Routine measurement of maximal exercise tolerance is performed with bicycle ergometry or treadmill tests under standardized conditions [13-15]. Major parameters of exercise tolerance are maximal oxygen consumption $\left(V^{\prime} \mathrm{O}_{2}, \max \right)$, endurance time or covered walking distance in treadmill tests, and maximal workload $\left(W^{\prime} \max \right)$ in bicycle ergometer tests [13]. Reference values are available for these parameters in normal adults [13-15] and children $[16,17]$. However, in children, body height, body weight (BW) and, in particular, fat-free mass (FFM) are associated with exercise parameters and with age. Exercise performance tests in $\mathrm{CF}$ are generally thought to give information on the patient's cardiopulmonary fitness, but this cannot be done unless exercise parameters are cor- rected for the patient's nutritional status [18]. Thus, apart from age, correction for nutritional status parameters is needed before conclusions on exercise parameters can be made [19]. MARCOTTE et al. [20] showed that, in CF patients, nutritional status plays a significant role in determining exercise capacity. From these observations, it follows that absolute values of exercise performance in $\mathrm{CF}$ patients should be compared with reference values for healthy children with correction for nutritional status. Reference values for $V^{\prime} \mathrm{O}_{2}$, max expressed per kilogram body weight $\left(V^{\prime} \mathrm{O}_{2}, \max \cdot \mathrm{kg}^{-1}\right)$ and $W^{\prime}$ max corrected for BW and FFM in children are available $[16,17,19]$. However, measurement of $V^{\prime} \mathrm{O}_{2}$, max requires sophisticated equipment, which is often unavailable outside specialized centres, whereas maximal work capacity can be measured in any setting when a bicycle ergometer is available.

The aim of the present study was to investigate whether $W^{\prime}$ max as compared to $V^{\prime} \mathrm{O}_{2}$, max can be used to assess exercise capacity in children with $\mathrm{CF}$ performing an incremental maximal exercise test, and which correction for nutritional status is useful.

\section{Subjects}

\section{Subjects and methods}

We studied 14 children with cystic fibrosis (mean age (SD) 14.8 (1.7) yrs, eight boys and six girls), who regularly attended the out-patient clinic of our hospital and 
were able to perform an exercise test. Other inclusion criteria were: a stable clinical condition; and a forced expiratory volume in one second (FEV1) $<90 \%$ of predicted value [21]. None of the patients showed clinical signs of asthma or atopy. All patients participated in gymnastics at school, three were also active in sports. None of the patients needed a daily oxygen supply. The patients' characteristics are presented in table 1.

\section{Methods}

An incremental maximal exercise test was performed on an electronically braked bicycle ergometer (Lode Examiner; Lode, Groningen, The Netherlands; accuracy $1 \%$ ), at least $1 \mathrm{~h}$ after a light lunch. In order to reach the subject's maximum in 8-15 min, stepwise increments of 10 or $15 \mathrm{~W} \cdot \mathrm{min}^{-1}$ were chosen; the $10 \mathrm{~W}$ protocol was used in patients with FEV $1<70 \%$ and/or body height $<1.70 \mathrm{~m}$, and the $15 \mathrm{~W}$ protocol in the remaining patients. $W^{\prime}$ max was defined as the highest workload maintained during the last $30 \mathrm{~s}$ of sustained workload. All tests were conducted by the same researcher (VAMG). The patients were encouraged to perform to the best of their abilities throughout the test.

Continuous breath by breath respiratory gas analysis and volume measurements were performed and automatically stored in a machine (Oxycon Champion; Jaeger, Breda, The Netherlands), using a Triple V valveless mouthpiece, while the nose was blocked with a clip. Oxygen and carbon dioxide concentrations were measured with a paramagnetic $\mathrm{O}_{2}$ analyser (Datex, Helsinki; accuracy $0.02 \% \mathrm{O}_{2}$ ) and an infra-red $\mathrm{CO}_{2}$ analyser (Datex, Helsinki; accuracy $0.01 \% \mathrm{CO}_{2}$ ), respectively. Internal gas and volume calibration was performed before each measurement according to the instructions of the manufacturer, as described by ZOLADZ and co-workers [23]. Oxygen consumption was computed automatically and gas volumes were expressed under standard conditions $\left(0^{\circ} \mathrm{C}\right.$ and 100 $\mathrm{kPa}$ ). Cardiac frequency (of 3-leads electrocardiograph (ECG); Hewlett-Packard, Amsbelveen, The Netherlands) and transcutaneous oxygen saturation (pulse oximetry; Nelcorr 200 E; Breda, the Netherlands) were also monitored continuously. At rest and $3 \mathrm{~min}$ after reaching $W ' \max$, capillary blood samples were taken from the

Table 1. - Characteristics of the patients studied

\begin{tabular}{lcc}
\hline Variable & Mean & SD \\
\hline Age yrs & 14.8 & 1.7 \\
FEV1 \% pred & 59 & 16 \\
FVC \% pred & 75 & 14 \\
MEF50 \% pred & 35 & 18 \\
RV/TLC \% & 46 & 7 \\
Height cm & 158.7 & 9.6 \\
Height Z-score sD units & -0.7 & 1.0 \\
Weight kg & 42.7 & 9.2 \\
Weight Z-score SD units & -1.4 & 0.6 \\
Fat-free mass kg & 35.8 & 8.3 \\
Stc, $\mathrm{O}_{2}$ at rest \% & 96 & 1 \\
Shwachman-score (0-100) & 71 & 11 \\
\hline Body weight and
\end{tabular}

Body weight and height for age were transformed into standard deviation scores (Z-scores, reference value from the National Center for Health Statistics, USA [22]). FEV1: forced expiratory volume in one second; FVC: forced vital capacity; MEF50: maximum expiratory flow at 50\% FVC; RV/TLC: residual volume to total lung capacity ratio; $\mathrm{Stc}_{\mathrm{t}} \mathrm{O}_{2}$ : transcutaneous oxygen saturation; $\%$ pred: percentage of predicted value. middle finger. The heparinized samples were placed on ice for determination of the plasma lactate concentration (enzymatic method, ACA ${ }^{\circledR}$ discrete clinical analyser; Du Pont de Nemours, Nemours, France). Efforts were considered to be at a maximum level if at least two out of three criteria were met: 1) cardiac frequency above 180 beats $\cdot \min ^{-1} ; 2$ ) maximal respiratory exchange ratio (i.e. ratio of carbon dioxide production over oxygen consumption $\left.\left(V^{\prime} \mathrm{CO}_{2} / V^{\prime} \mathrm{O}_{2}\right)\right)$ above 1.0 ; and 3 ) increase in lactate concentration above threshold levels in agematched controls as described by DAviEs et al. [16]. All patients fulfilled at least two criteria (table 2).

BW was measured with an electronic scale (ID1 multimap; Mettler, Tiel, The Netherlands; accuracy 20 g). FFM was calculated from the measurements of the four leftsided skinfolds (biceps, triceps, subscapular region and above the crista iliaca) with a Holtain calliper (Crymych, UK; accuracy $0.1 \mathrm{~mm}$ ), according to the method described by DuRnin and RAHAMAn [24].

The study was approved by the Medical Ethics Committee and the Research Council of the University Hospital for Children and Youth "Wilhelmina Children's Hospital" and informed consent was obtained in all cases.

\section{Statistical analysis}

Kolmogorov-Smirnov goodness-of-fit tests showed no significant deviations with respect to the assumption of normality of distribution for all variables. Correlation analyses (Pearson's r) were performed for $W^{\prime} \max , V^{\prime} \mathrm{O}_{2}$, max, BW and FFM. The ratios of $W^{\prime} \max$ and $V^{\prime} \mathrm{O}_{2}$, max both with BW and FFM were calculated. Standard deviation scores (Z-scores, expressed in SD units) were calculated for $W^{\prime} \max , W^{\prime} \max / \mathrm{BW}$ ratio, $W^{\prime} \max / \mathrm{FFM}$ ratio and $V^{\prime} \mathrm{O}_{2}$, max, $V^{\prime} \mathrm{O}_{2}, \max / \mathrm{BW}$ ratio, $V^{\prime} \mathrm{O}_{2}$, max/FFM ratio from reference values obtained in healthy Dutch children $[19,25]$. Individual values were also compared to the 3 rd percentile $\left(\mathrm{P}_{3}\right)$ of the reference population (the $\mathrm{P}_{3}$ corresponds with a Z-score of -1.88). Mean differences between Z-scores and $95 \%$ confidence intervals $(95 \% \mathrm{CI})$ were calculated from paired t-tests. The Statistical Package for the Social Sciences (SPSS) $\mathrm{PC}^{+}$package (version 5.0) was used for analysis [26]. A p-value of less than 0.05 was considered significant.

\section{Results}

In all patients, exercise tests met the criteria for maximal performance. Exercise parameters are summarized in table 2. Results for $W^{\prime} \max$ and $V^{\prime} \mathrm{O}_{2}$, max and the Zscores of these parameters in individual patients before and after correction for nutritional status are presented in table 3. BW and FFM were associated with $W^{\prime} \max (\mathrm{r}=0.66$; $\mathrm{p}<0.01)$ and $(0.79 ; \mathrm{p}<0.001)$, respectively and $V^{\prime} \mathrm{O}_{2}$, $\max$

Table 2. - Exercise parameters at peak exercise

\begin{tabular}{lcc}
\hline Variables & & \\
\hline Workload W & $122 \pm 42$ & $(70-202)$ \\
$V^{\prime} \mathrm{O}_{2} \mathrm{~mL}$ & $1732 \pm 482$ & $(1204-2521)$ \\
$f_{\mathrm{C}}$ beats $\cdot \mathrm{min}^{-1}$ & $173 \pm 12$ & $(142-197)$ \\
Plasma lactate concentration $\mathrm{mmol} \cdot \mathrm{L}^{-1}$ & $7.4 \pm 2.7$ & $(3.2-13.2)$ \\
Respiratory exchange ratio & $1.16 \pm 0.08$ & $(1.07-1.36)$ \\
$\mathrm{Stc}_{\mathrm{O}} \%$ & $93 \pm 2$ & $(89-97)$ \\
$V^{\prime} \mathrm{O}_{2}$ per heart beat $\mathrm{mL} \cdot$ beat $^{-1}$ & $9.9 \pm 2.6$ & $(7.0-14.2)$ \\
\hline
\end{tabular}

Values are presented as mean $\pm \mathrm{SD}$, and range in parenthesis. $V^{\prime} \mathrm{O}_{2}$ : oxygen consumption; $f_{\mathrm{C}}$ : cardiac frequency; $\mathrm{Stc}_{\mathrm{t}, \mathrm{O}_{2}}$ : transcutaneous oxygen saturation. 
Table 3. - Absolute values of maximal workload and maximal oxygen consumption, and standard deviation scores (Z) with and without correction for nutritional status

\begin{tabular}{|c|c|c|c|c|c|c|c|c|}
\hline $\begin{array}{l}\mathrm{Pt} \\
\text { No. }\end{array}$ & $\begin{array}{c}W_{\text {max }}^{\prime} \\
\mathrm{W}\end{array}$ & $\begin{array}{l}\mathrm{Z}\left(W^{\prime} \max \right) \\
\text { SD unit }\end{array}$ & $\begin{array}{l}\mathrm{Z}\left(W^{\prime} \max / \mathrm{BW}\right) \\
\text { SD unit }\end{array}$ & $\begin{array}{c}\mathrm{Z}\left(W^{\prime} \max / \mathrm{FFM}\right) \\
\text { SD unit }\end{array}$ & $\begin{array}{l}V^{\prime} \mathrm{O}_{2}, \max \\
\mathrm{mL} \cdot \min ^{-1}\end{array}$ & $\begin{array}{l}\mathrm{Z}\left(V^{\prime} \mathrm{O}_{2}, \max \right) \\
\text { SD unit }\end{array}$ & $\begin{array}{c}\mathrm{Z}\left(V^{\prime} \mathrm{O}_{2}, \max / \mathrm{BW}\right) \\
\mathrm{SD} \text { unit }\end{array}$ & $\begin{array}{c}\mathrm{Z}\left(V^{\prime} \mathrm{O}_{2}, \max / \mathrm{FFM}\right) \\
\text { SD unit }\end{array}$ \\
\hline 1 & 202 & -1.91 & -0.86 & -1.48 & 2521 & -1.20 & 0.50 & -0.07 \\
\hline 2 & 70 & -4.77 & -4.83 & -6.17 & 1216 & -2.46 & -2.32 & -3.75 \\
\hline 3 & 90 & -2.84 & -1.88 & -2.68 & 1379 & -1.74 & -0.06 & -0.85 \\
\hline 4 & 150 & -2.10 & -1.94 & -3.14 & 1857 & -0.86 & -0.70 & -1.87 \\
\hline 5 & 105 & -2.70 & -1.57 & -2.17 & 1639 & -0.65 & 1.54 & 1.23 \\
\hline 6 & 188 & -3.03 & -3.76 & -3.90 & 2497 & -1.76 & -2.46 & -2.49 \\
\hline 7 & 143 & -2.93 & -1.43 & -1.60 & 1806 & -2.24 & 0.22 & 0.12 \\
\hline 8 & 165 & -4.57 & -2.91 & -3.38 & 2069 & -3.08 & -1.90 & -2.48 \\
\hline 9 & 80 & -3.63 & -2.96 & -3.31 & 1351 & -1.37 & -0.32 & -0.51 \\
\hline 10 & 100 & -3.77 & -3.87 & -3.60 & 1714 & -1.21 & -1.70 & -1.65 \\
\hline 11 & 80 & -3.63 & -3.16 & -3.31 & 1204 & -1.49 & -1.24 & -0.86 \\
\hline 12 & 100 & -3.42 & -2.58 & -3.45 & 1303 & -2.74 & -2.08 & -3.20 \\
\hline 13 & 100 & -4.32 & -4.14 & -4.64 & 1285 & -3.54 & -3.22 & -3.64 \\
\hline 14 & 135 & -3.19 & -2.16 & -3.02 & 2416 & -0.21 & 1.86 & 2.64 \\
\hline Mean & 122 & -3.34 & -2.72 & -3.28 & 1733 & -1.75 & -0.85 & -1.24 \\
\hline SD & 42 & 0.85 & 1.15 & 1.19 & 482 & 0.96 & 1.54 & 1.86 \\
\hline \multicolumn{2}{|c|}{ p-value* } & $<0.001$ & $<0.001$ & $<0.001$ & & $<0.001$ & 0.08 & 0.05 \\
\hline
\end{tabular}

$W^{\prime}$ max: maximal workload; $\mathrm{Z}\left(W^{\prime} \max \right)$ : sD score of maximal workload; $\mathrm{Z}\left(W^{\prime} \max / \mathrm{BW}\right)$ : sD score of the ratio of maximal workload and body weight; $\mathrm{Z}\left(W^{\prime} \max / \mathrm{FFM}\right)$ : $\mathrm{SD}$ score of the ratio of maximal workload and fat-free mass; $V^{\prime} \mathrm{O}_{2}$,max: maximal oxygen consumption; $\mathrm{Z}\left(V^{\prime} \mathrm{O}_{2}, \mathrm{max}\right)$ : $\mathrm{SD}$ score of the ratio of maximal oxygen consumption; $\mathrm{Z}\left(V^{\prime} \mathrm{O}_{2}, \max / \mathrm{FFM}\right)$ : sD score of the ratio of maximal oxygen consumption and fat-free mass. *: t-test, comparing mean Z-score of cystic fibrosis $(\mathrm{CF})$ patients with median reference population (which corresponds with Z-score of 0 ).

$(\mathrm{r}=0.63 ; \mathrm{p}<0.01)$ and $(0.74 ; \mathrm{p}<0.001)$, respectively. Results for $V^{\prime} \mathrm{O}_{2}$, max and $W^{\prime} \max$ showed a high correlation within the patient group $(\mathrm{r}=0.91 ; \mathrm{p}<0.001)$. However, $W^{\prime} \max$ was below the 3 rd percentile in all patients, but only 5 out of 14 patients had a $V^{\prime} \mathrm{O}_{2}, \max <\mathrm{P}_{3}$. The mean Z-score for $V^{\prime} \mathrm{O}_{2}$, max was significantly higher than the Z-score for $W^{\prime} \max$ (mean difference 1.59; 95\% CI 1.14-2.04 sD units).

Comparisons of the standardized exercise parameters showed significantly higher Z-scores for $W^{\prime}$ max/BW ratio than for $W^{\prime} \max$ (mean difference $0.63 ; 95 \%$ CI $0.24-1.01$ SD units), but not for $W^{\prime} \max / \mathrm{FFM}$ ratio and $W^{\prime} \max$ (mean difference -0.07 ; 95\% CI -0.52-0.38). Likewise, for $V^{\prime} \mathrm{O}_{2}$,max, significantly higher Z-score values existed after correction for $\mathrm{BW}$ (mean difference between $\mathrm{Z}\left(V^{\prime} \mathrm{O}_{2}, \mathrm{max} /\right.$ $\mathrm{BW})$ and $\mathrm{Z}\left(V^{\prime} \mathrm{O}_{2}, \max \right) 0.91$; $95 \%$ CI 0.32-1.49), but standardized scores for $V^{\prime} \mathrm{O}_{2}$, max/FFM ratio and $V^{\prime} \mathrm{O}_{2}$, max were not significantly different (mean difference 0.51 ; $95 \%$ CI $-0.22-1.24)$. Nine of the 14 patients had a $V^{\prime} \mathrm{O}_{2}, \max / \mathrm{BW}>\mathrm{P}_{3}$, and three patients had a $V^{\prime} \mathrm{O}_{2}$, max exceeding the median of the reference population.

\section{Discussion}

In this study, we compared maximal workload measurements in children with $\mathrm{CF}$ and addressed the correction of $W^{\prime} \max$ and $V^{\prime} \mathrm{O}_{2}$, max for nutritional status. Our results showed that in the $\mathrm{CF}$ patients, Z-scores for $W^{\prime} \max / \mathrm{BW}$ ratio reach significantly higher values than Z-scores for $W^{\prime} \max$ and $W^{\prime} \max / F F M$ ratio. This was also found for the respective parameters of $V^{\prime} \mathrm{O}_{2}$, max. In normal children, there is a higher correlation between FFM and $W^{\prime} \max$ and $V^{\prime} \mathrm{O}_{2}$, max than between $\mathrm{BW}$ and these exercise parameters [19], as FFM is a better correlate for body muscle mass than BW. The clinically declined CF patients in this study also showed high correlations between $W^{\prime} \max \left(\right.$ and $V^{\prime} \mathrm{O}_{2}$, max) and FFM. Moreover, the Z-scores for these exercise parameters after correction for FFM were not significantly different from the uncorrected Z-scores, whereas Z-scores with correction for BW were significantly higher. This can be explained by the greater level of fat depletion in undernourished $\mathrm{CF}$ patients, resulting in a higher proportion of FFM per unit of BW, and by the fact that exercise capacity is mainly dependent on FFM. Thus, correction for BW seems to overestimate the work capacity in patients with $\mathrm{CF}$. These results are in agreement with those in the study by LANDS et al. [18], in which differences in $V^{\prime} \mathrm{O}_{2}$, max between adult $\mathrm{CF}$ patients and controls persisted after correction for FFM. The results suggest that $W^{\prime} \max$ and $V^{\prime} \mathrm{O}_{2}$, max can both be used for the follow-up of children with $\mathrm{CF}$.

Although the highly significant correlation between $W^{\prime} \max$ and $V^{\prime} \mathrm{O}_{2}$, max in the present study group $(\mathrm{r}=0.91$; $\mathrm{p}<0.001)$ is in agreement with results of previous studies in healthy subjects $[13,15,27]$, we found a significant difference between standardized $W^{\prime}$ max and $V^{\prime} \mathrm{O}_{2}$, max in the children with $\mathrm{CF}$. In this group of patients with mild-tomoderate symptoms, $V^{\prime} \mathrm{O}_{2}$, max and even more the ratios $V^{\prime} \mathrm{O}_{2}$, max/BW and $V^{\prime} \mathrm{O}_{2}$,max/FFM had persistently higher Z-scores than their $W^{\prime}$ max counterparts (table 3 ). Surprisingly, the patients had a relatively good level of $V^{\prime} \mathrm{O}_{2}$, max and $V^{\prime} \mathrm{O}_{2}$, max $/ \mathrm{BW}$ (nine out of 14 patients were in the normal range). However, these children had a high degree of impairment with respect to $W^{\prime} \max \left(<\mathrm{P}_{3}\right.$ in all patients). These results are different from those of LANDS et al. [18], who found no excessive $V^{\prime} \mathrm{O}_{2}$, max as compared to $W^{\prime}$ max in a group of 14 adult patients with CF. Methodological factors in the measurement of $W^{\prime} \max$ and $V^{\prime} \mathrm{O}_{2}$, max are unlikely to explain the discrepancy between $W^{\prime} \max$ and $V^{\prime} \mathrm{O}_{2}$, max in the children in the present study.

Thus, biological explanations for the observed discrepancy in results for $W^{\prime} \max$ and $V^{\prime} \mathrm{O}_{2}$, max should be considered. Pulmonary function in these patients with CF was diminished, limiting their maximal oxygen uptake in the lungs. However, both before and after correction for $\mathrm{BW}, V^{\prime} \mathrm{O}_{2}$, max in the CF patients was better preserved than $W^{\prime}$ max output. If oxygen uptake in the lungs (or oxygen transport by the blood) was the limiting factor for maximal performance in this patient group, we cannot explain the latter finding. In children, muscle mass 
(and FFM and BW) is associated with $W^{\prime} \max$ and also with $V^{\prime} \mathrm{O}_{2}$,max. The lower BW and FFM in the CF patients as compared to their peers in the reference population would affect both $W^{\prime} \max$ and $V^{\prime} \mathrm{O}_{2}$, max, and thus differences in nutritional status do not seem to explain the observed discrepancies between the Z-scores for $W^{\prime} \max$ and $V^{\prime} \mathrm{O}_{2}$, max. The higher standardized scores for $V^{\prime} \mathrm{O}_{2}$, max as compared to $W^{\prime} \max$ suggest that, relative to healthy peers in the Dutch reference population, the children with CF in the present study consumed more oxygen at a given level of workload. This hypothesis is supported by a previous study in children with $\mathrm{CF}$, which showed a lower efficiency of adenosine triphosphate (ATP) synthesis during in vivo oxidative power generation in skeletal muscle as compared to controls [28]. However, even after correcting maximal workload for age, gender, and nutritional status, other clinical factors, such as drugs, bacterial colonization and genotype, may influence maximal work performance in children with $\mathrm{CF}$, and thus no inferences can be made on the cause of the discrepancy between $V^{\prime} \mathrm{O}_{2}$, max and $W^{\prime} \max$ in this patient group. Further studies in patients with $\mathrm{CF}$ in different clinical conditions and in different age groups are needed to address the observation of diminished work performance in relation to oxygen consumption.

We conclude that, in children with mild-to-moderate cystic fibrosis, maximal work output can be used as a parameter for physical fitness. Correction for nutritional status should include the ratio of maximal workload and fat-free mass, which according to our results seems a useful parameter for that purpose. In the children with cystic fibrosis, strong associations existed between maximal workload and maximal oxygen consumption. As compared to healthy children, maximal workload in the patients with cystic fibrosis were lower than maximal oxygen consumption, after correction for nutritional status. When this is taken into account, maximal workload and the ratio of maximal workload and fat-free mass are an alternative to maximal oxygen consumption and the ratio of maximal oxygen consumption and fat-free mass for the assessment, and especially the follow-up, of exercise tolerance in clinically declined children and adolescents with cystic fibrosis. This is of particular importance for settings where equipment for gas analysis is not available.

Acknowledgements: The authors thank J.A.J. Faber (Utrecht University, Centre for Biostatistics) for statistical comments, and Nutricia B.V. (Zoetermeer, The Netherlands) for financial support.

\section{References}

1. Nixon PA, Orenstein DM, Kelsey SF, Doerskuk CF. The prognostic value of exercise testing in patients with cystic fibrosis. N Engl J Med 1992; 327: 1785-1788.

2. Corey M, McLaughlin MC, Williams M, Levison H. A comparison of survival, growth and pulmonary function in patients with cystic fibrosis in Boston and Toronto. J Clin Epidemiol 1988; 41: 583-591.

3. Stanghelle JK. Physical exercise for patients with cystic fibrosis: a review. Int J Sports Med 1988; 9: 6-18.

4. Orenstein DM, Franklin BA, Doershuk CF, Hellerstein HK, Germann KJ, Horowitz JG. Exercise conditioning and cardiopulmonary fitness in cystic fibrosis. Chest 1981; 80: 392-398.

5. Blomquist M, Freyschuss U, Wiman LG, Strandvik B. Physical activity and self-treatment in cystic fibrosis. Arch Dis Child 1986; 61: 362-367.

6. O'Neill PA, Dodds M, Phillips B, Poole J, Webb AK. Reg- ular exercise and the reduction of breathlessness in patients with cystic fibrosis. Br J Dis Chest 1987; 81: 62-69.

7. Strauss GD, Osher A, Wang CI, et al. Variable weight training in cystic fibrosis. Chest 1987; 92: 273-276.

8. Heyerman HGM, Bakker W, Sterk PJ, Dijkman JH. Oxygen-assisted exercise training in adult cystic fibrosis patients with pulmonary limitation to exercise. Int $J$ Rehab Res 1991; 14: 101-115.

9. Jong de W, Grevink RG, Roorda RJ, Kaptein AA, Schans van der CP. Effect of a home exercise training program in patients with cystic fibrosis. Chest 1994; 105: 463-468.

10. Zach M, Oberwaldner B, Hausler F. Cystic fibrosis: physical exercise versus chest physiotherapy. Arch Dis Child 1982; 57: 587-589.

11. Edlund ED, French RW, Herbst JJ, Ruttenberg HD, Ruhling $\mathrm{RO}$, Adams AD. Effect of a swimming program on children with cystic fibrosis. Am J Dis Child 1986; 140: 80-83.

12. Andreasson B, Jonson B, Kornfalt R, Nordmark E, Sandstrom S. Long-term effects of physical exercise on working capacity and pulmonary function in cystic fibrosis. Acta Paediatr Scand 1987; 77: 70-75.

13. Wasserman K, Hansen JE, Sue DY, Whipp BJ. Principles of exercise testing and interpretation. Philadelphia, Lea and Febiger, 1987.

14. Åstrand PO, Rodahl K. In: Textbook of Work Physiology. New York, McGraw-Hill, 1976.

15. Jones NL, Makrides L, Hitchcock C, Chypcar T, McCartney N. Normal standards for an incremental progressive cycle ergometer test. Am Rev Respir Dis 1985; 131: 700-708.

16. Davies CTM, Barnes C, Godfrey S. Body composition and maximal exercise performance in children. Hum Biol 1972; 44: 195-214.

17. Binkhorst RA, Saris WHM, Noordeloos AM, Hof van 't MA, Haan de AFJ. Maximal oxygen consumption of children (6 to 18 years) predicted from maximal and submaximal values in treadmill and bicycle tests. In: Rutenfranz J, Mocellin R, Klimt F, eds. Children and Exercise. XII. Champaign, IL, Human Kinetics, 1986; pp. 227-232.

18. Lands LC, Heigenhauser JF, Jones NL. Analysis of factors limiting maximal exercise performance in cystic fibrosis. Clin Sci 1992; 83: 391-397.

19. Gulmans VAM, Meer de K, Binkhorst RA, Helders PJM, Saris W. Reference values for maximum work capacity in relation to body composition in healthy Dutch children. Eur Respir J 1997; 10: 94-97.

20. Marcotte JE, Canny GJ, Grisdale R, et al. Effects of nutritional status on exercise performance in advanced cystic fibrosis. Chest 1986; 90: 375-379.

21. Zapletal A, Zamanek M, Paul T. In: Lung Function in Children and Adolescents; Methods and Reference Values. Progress in Respiratory Disease. Basel, Herzog, 1987.

22. Hamill P, Drizd T, Johnson C, Reed R, Roche A, Moore W. Physical growth: National Center for Health Statistics percentiles. Am J Clin Nutr 1979; 32: 607-627.

23. Zoladz JA, Rademaker ACHJ8, Sargeant AJ. Nonlinear relationship between oxygen uptake and power output at high intensities of exercise in humans. J Physiol 1995; 4881: 211-217.

24. Durnin JVGA, Rahaman MM. The assessment of the amount of fat in the human body from the measurement of skinfold thickness. Br J Nutr 1967; 21: 681-689.

25. Binkhorst RA, Hof van 't MA, Saris WHM. Maximum exercise in children; reference values for 6-18 year old girls and boys. The Hague, Dutch Heart Association, 1992.

26. Nie NH. In: Statistical Package for the Social Sciences. New York, McGraw Hill, 1975.

27. Godfrey S. In: Exercise testing in children. London, Saunders, 1974.

28. Meer de K, Jeneson JAL, Gulmans VAM, Laag van der J, Berger R. Efficiency of oxidative work performance of skeletal muscle in patients with cystic fibrosis. Thorax 1995; 50: 980-983. 